\title{
Penentuan Daerah Prioritas di Wilayah Pelayanan Bandung Utara berdasarkan Parameter Fungsi dan Nilai Daerah
}

\author{
PEPIN SEPTIANI ${ }^{1}$, SITI AINUN ${ }^{1}$ \\ 1. Jurusan Teknik Lingkungan, Fakultas Teknik Sipil dan Perencanaan, Institut \\ Teknologi Nasional, Bandung \\ Email :pepinseptiani@gmail.com
}

\begin{abstract}
ABSTRAK
Wilayah Pelayanan (WP) Bandung Utara merupakan salah satu wilayah pelayanan sampah di Kota Bandung yang terdiri dari 7 kecamatan dan 31 kelurahan dengan karakteristik yang beragam. Tujuan studi ini menentukan daerah prioritas di WP Bandung Utara berdasarkan parameter fungsi dan nilai daerah pada SNI 19-2454-2002. Studi dilakukan dengan menentukan kriteria penilaian, identifikasi sumber dan jenis data yang tersedia, dan penentuan data yang digunakan, menyusun penilaian penentuan daerah prioritas dengan pembuatan standar kelas penilaian dan skoring, pembobotan nilai akhir dan pembuatan peta daerah prioritas. Daerah prioritas 1 yaitu Kelurahan Pasteur, Sukagalih, Citarum dan Tamansari. Daerah prioritas 2 yaitu Kelurahan Lebak Gede, Sadang Serang, Sekeloa, Gegerkalong, Sarijadi, Sukabungah, Cihaurgeulis, Sukaluyu, Cikutra dan Cihapit, daerah prioritas 3 yaitu Kelurahan Ciumbuleuit, Hegarmanah, Ledeng, Cipaganti, Dago, Lebak Siliwangi, Isola, Sukarasa, Cipedes, Sukawarna, Cigadung, Neglasari, Cicadas Padasuka, Pasirlayung, Sukamaju, dan Sukapada.
\end{abstract}

Kata kunci: Wilayah pelayanan , Fungsi dan nilai daerah

\begin{abstract}
Service Area North Bandung is one of the areas of waste management services in Bandung, which consists of 7 districts and includes 31 villages with various characteristics. The purpose of this study was to determine priority areas in North Bandung WP by parameter function and values based on SNI 19-24542002. The study was done by determination of the assessment criteria, identification of sources and types of data available, and the determination of the data used, then make assessment determining the priority areas to manufacture class standards of assessment and scoring, weighting the value of the final and mapping areas of priority. The priority area 1 of waste management services were the Village Pasteur, Sukagalih, Citarum and Tamansari. The priority area 2 comprised the Village Lebak Gede, Sadang Serang, Sekeloa, Gegerkalong, Sarijadi, Sukabungah, Cihaurgeulis, Sukaluyu, Cikutra and Cihapit. The priority area 3 consisted of the Village Ciumbuleuit, Hegarmanah, Ledeng, Cipaganti, Dago, Lebak Siliwangi, Isola, Sukarasa, Cipedes, Sukawarna, Cigadung, Neglasari, Cicadas Padasuka, Pasirlayung, Sukamaju, and Sukapada.
\end{abstract}

Keywords: The area of services, functions and value of the area 


\section{PENDAHULUAN}

Kota Bandung memiliki 4 wilayah pelayanan sampah yaitu wilayah pelayanan Bandung Barat, Bandung Utara, Bandung Selatan dan Bandung Timur. Pengelompokan wilayah pelayanan yang saat ini berjalan adalah berdasarkan zonasi artinya hanya mengelompokkan daerah-daerah dengan jarak terdekat dengan pengelolaan yang sama. Pada kondisi eksisting setiap wilayah memiliki kompleksitas dan heterogenitas daerah masing-masing, termasuk Wilayah Pelayanan Bandung Utara. Jika penerapan pengelolaan yang sama di wilayah yang memiliki karakteristik berbeda maka dapat memunculkan permasalahan dalam sistem pengelolaan sampah seperti munculnya TPS liar di setiap daerah.

Permasalahan tersebut dapat dihindari dengan adanya pembentukan daerah prioritas di Wilayah Pelayanan Bandung Utara. Daerah prioritas adalah daerah yang harus dilayani lebih intens dibandingkan yang lain. Pengelompokkan daerah ini berdasarkan karakteristik daerah yang serupa sehingga sistem pengelolaan sampah yang diaplikasikan pun sama. Dengan diketahuinya daerah yang harus diprioritaskan sistem pengelolaan sampahnya akan meningkatkan tingkat pelayanan sampah di Wilayah Pelayanan Bandung Utara.

Wilayah Pelayanan Bandung Utara terletak di bagian utara Kota Bandung yang terdiri dari 7 Kecamatan yang mencakup 31 kelurahan. Fungsi dan nilai daerah dari ketujuh kecamatan ini beragam, mulai dari daerah yang berfungsi sebagai daerah pemukiman padat penduduk, pemukiman rendah penduduk, daerah yang digunakan sebagai ruang terbuka hijau dan fungsi daerah lainnya. Semakin penting fungsi dan nilai suatu daerah, maka daerah tersebut harus semakin di prioritaskan. Skala kepentingan fungsi dan nilai daerah dapat dilihat dari besarnya nilai kerawanan sanitasi dan potensi ekonomi yang tercantum dalam SNI 19-2454-2002.

Maksud dari penerapan perencanaan ini untuk mengetahui kelurahan mana saja yang menjadi daerah prioritas dengan mempertimbangkan karakteristik daerah tersebut berdasarkan parameter fungsi dan nilai daerah. Tujuannya untuk mengevaluasi parameter fungsi dan nilai daerah dan menyusun standar kelas penilaian untuk penentuan daerah prioritas.

\section{METODOLOGI}

Tahap yang dilakukan dalam perencanaan ini tercantum dalam Gambar 2.1.

\subsection{Evaluasi parameter fungsi dan nilai daerah berdasarkan SNI 2.1.1 Penentuan kriteria penilaian}

Pada parameter fungsi dan nilai daerah tercantum 6 (enam) sub-parameter yang terdiri dari daerah di jalan protokol; komersil; perumahan teratur; industri; jalan,taman dan hutan kota; daerah perumahan tidak teratur, selokan. Dari ke enam sub-parameter tersebut belum jelas kriteria penilaiannya sehingga dilakukan penentuan kriteria penilaiannya. Penentuan kriteria penilaian untuk masing-masing sub-parameter berdasarkan pada satuan yang umum digunakan. Seperti satuan yang umum digunakan untuk jalan adalah panjang jalan, lebar jalan dan/atau luas jalan. 

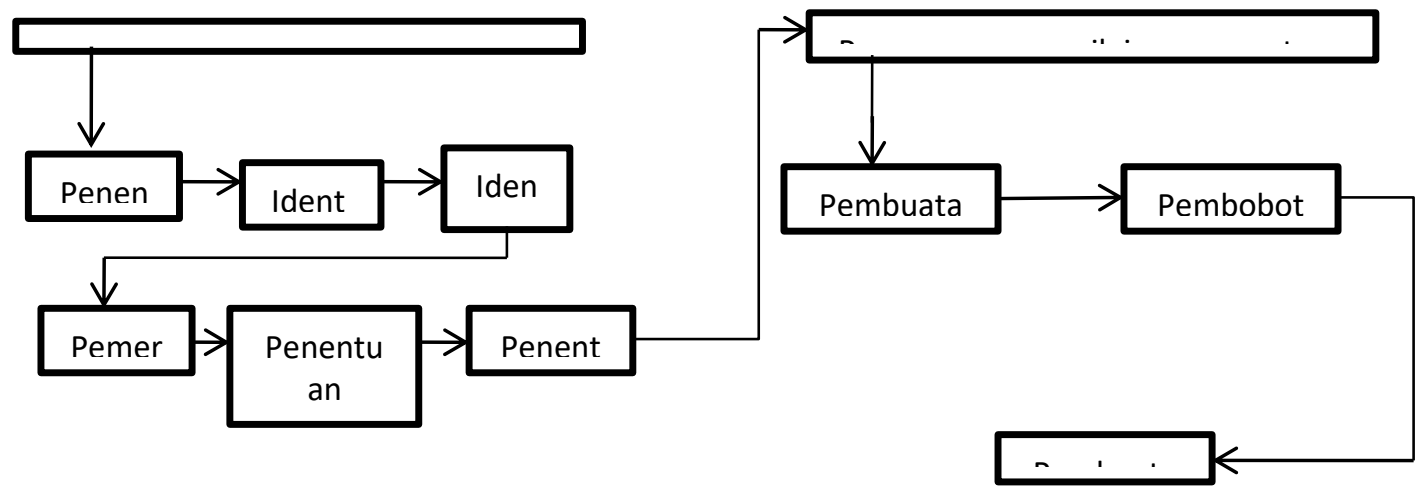

\section{Gambar 2.1 Metodologi perencanaan}

Sumber : Hasil analisa, 2018

\subsubsection{Identifikasi sumber data}

Hal yang dilakukan dalam tahap ini yaitu mengidentifikasi kemungkinan sumber data untuk menunjang kriteria penilaian dari masing-masing sub-parameter dengan cara mencari tahu melalui berbagai media termasuk media sosial dan dokumen terkait instansi yang membidangi keenam sub-parameter. Kunjungan secara langsung ke instansi tersebut dalam rangka melakukan wawancara dan meminta data atau dokumen yang dibutuhkan. Instansi yang dimaksud diantaranya Badan Perencanaan Pembangunan Penelitian dan Pengembangan (BAPPELITBANG), Badan Pusat Statistik (BPS), Dinas Pekerjaan Umum, Dinas Penataan Ruang, Dinas Pemukiman, Pertanahan dan Pertamanan, Dinas Komunikasi dan Informatika (DISKOMINFO), City Plan Kota Bandung, dan seluruh kantor kecamatan di WP Bandung Utara diantaranya Kantor Kecamatan Cidadap, Coblong, Sukasari, Sukajadi, Cibeunying Kaler, Cibeunying Kidul, dan Bandung Wetan.

\subsubsection{Identifikasi jenis data yang tersedia}

Dari berbagai dokumen dan file yang diperoleh dari instansi-instansi tersebut selanjutnya diidentifikasi data apa saja yang dapat digunakan untuk mewakili sub-parameter dalam parameter fungsi dan nilai daerah dengan cara studi literature terkait keseragaman data yang tersedia dengan sub-parameter yang dimaksud.

\subsubsection{Pemeriksaan kelengkapan data}

Dari berbagai dokumen dan file yang diperoleh dari instansi-instansi tersebut selanjutnya diidentifikasi data apa saja yang lengkap dan dapat digunakan untuk mewakili subparameter dalam parameter fungsi dan nilai daerah dengan cara studi literature terkait keseragaman data yang tersedia dengan sub-parameter yang dimaksud.

\subsubsection{Penentuan pengembangan, modifikasi dan/atau penghilangan sub- parameter}

Pada tahap ini, data yang sudah lengkap selanjutnya ditentukan apakah harus dilakukan pengembangan, modifikasi dan/atau dihilangkan agar data seragam dan dapat mewakili subparameter yang dimaksud.

\subsubsection{Penentuan data yang digunakan}

Tahap terakhir dalam evaluasi parameter fungsi dan nilai daerah adalah menentukan data yang akan digunakan dengan meninjau kelengkapan data, kelayakan penggunaan data dari segi tahun, dan kesamaan data yang tersedia dengan sub-parameter yang dimaksud. 


\subsection{Penyusunan penilaian penentuan daerah prioritas berdasarkan parameter fungsi dan nilai daerah}

\subsubsection{Pembuatan standar kelas penilaian dan skoring}

Pembuatan standar kelas bertujuan untuk penentuan skor yang harus ditetapkan. Standar kelas ini didasari dari nilai data terbesar dan terkecil yang selanjutnya dibagi kedalam kelas yang diinginkan. Skor untuk penilaian sub-parameter dibagi menjadi 3 kelas yaitu rendah, sedang dan tinggi. Penentuan skor berdasarkan justifikasi dan teori terkait skala prioritas pengelolaan sampah.

\subsubsection{Pembobotan nilai akhir berdasarkan SNI}

Setelah diperoleh skor setiap sub-parameter di masing-masing kelurahan kemudian dilakukan pembobotan nilai akhir yang bertujuan untuk mengelompokkan daerah prioritas di Wilayah Bandung Utara dengan mengacu pada nilai kerawanan sanitasi dan potensi ekonomi dari masing-masing sub-parameter yang tercantum dalam SNI. Output yang dihasilkan dari tahap ini adalah daerah prioritas.

\subsubsection{Pembuatan peta daerah prioritas}

Daerah prioritas yang dihasilkan dari pembobotan berdasarkan SNI, kemudian di plot ke dalam peta dengan pemberian warna berbeda untuk setiap daerah prioritas. Tujuan pemberian warna ini untuk memisahkan kelurahan yang lebih prioritas dibandingkan kelurahan lain

\section{HASIL DAN PEMBAHASAN}

\subsection{Evaluasi parameter fungsi dan nilai daerah berdasarkan SNI}

\subsubsection{Pembuatan kriteria penilaian}

Parameter untuk menentukan daerah pelayanan yang tercantum dalam SNI 19-2454-2002 tentang Tata Cara Teknik Operasional Pengelolaan Sampah Perkotaan diantaranya :

1. Fungsi dan Nilai Daerah

2. Kepadatan penduduk

3. Kondisi lingkungan

4. Tingkat pendapatan penduduk

5. Kondisi topografi

6. Daerah pelayanan

Pada perencanaan ini hanya akan membahas terkait parameter fungsi dan nilai daerah karena parameter ini memiliki sub-parameter yang lebih spesifik tetapi belum jelas kriteria penilaian untuk masing-masing sub-parameternya. Karena itu dibuatlah kriteria penilaian untuk masing-masing sub-parameter agar dapat diterapkan dengan lebih jelas dan mudah. Pembuatan kriteria parameter ini berdasarkan satuan yang umum dari sub-parameter yang dimaksud, seperti satuan yang umum digunakan untuk suatu jalan adalah panjang jalan bukan luas jalan sedangkan satuan untuk suatu daerah biasanya menggunakan luas. Kriteria penilaian tersebut tercantum dalam Tabel 3.1.

Tabel 3.1 Kriteria penilaian parameter fungsi dan nilai daerah

\begin{tabular}{cll}
\hline No & Sub-parameter & Kriteria penilaian \\
\hline 1 & Daerah di jalan protokol/pusat kota & $\begin{array}{l}\text { Panjang jalan, lebar jalan, luas jalan dan } \\
\text { persentase jalan }\end{array}$ \\
\hline 2 & Daerah komersial & Luas lahan, jumlah komersil, dan \\
\hline
\end{tabular}




\begin{tabular}{cll}
\hline No & Sub-parameter & Kriteria penilaian \\
\hline 3 & Daerah pemukiman teratur & $\begin{array}{l}\text { persentase daerah komersil } \\
\text { dan persentase daerah pemukiman } \\
\text { teratur }\end{array}$ \\
\hline 4 & $\begin{array}{l}\text { Daerah perumahan tidak teratur, } \\
\text { selokan }\end{array}$ & $\begin{array}{l}\text { Luas lahan, jumlah pemukiman tidak } \\
\text { teratur, dan persentase daerah } \\
\text { pemukiman tidak teratur }\end{array}$ \\
\hline 5 & Daerah industri & $\begin{array}{l}\text { Luas lahan jumlah industri, dan } \\
\text { persentase daerah industri }\end{array}$ \\
\hline 6 & Jalan, taman, dan hutan kota & $\begin{array}{l}\text { Luas lahan jumlah taman dan hutan kota, } \\
\text { dan persentase taman dan hutan kota }\end{array}$ \\
\hline
\end{tabular}

Sumber : Hasil Analisa, 2018

\subsubsection{Identifikasi sumber data}

Berdasarkan studi literatur, instansi-instansi yang memegang hubungan erat dengan subparameter yang dimaksud dalam parameter fungsi dan nilai daerah tercantum dalam Tabel 3.2.

Tabel 3.2 Sumber data

\begin{tabular}{|c|c|c|}
\hline No & Sub-parameter & Sumber data \\
\hline \multirow[t]{2}{*}{1} & Daerah di jalan & Dinas Pekerjaan umum yang membidangi binamarga; \\
\hline & protokol/pusat kota & $\begin{array}{l}\text { BAPPELITBANG; Dinas Penataan Ruang; Kantor } \\
\text { Kecamatan: DISKOMINFO }\end{array}$ \\
\hline 2 & Daerah komersial & $\begin{array}{l}\text { BAPPELITBANG; BPS; Dinas Penataan Ruang; Kantor } \\
\text { Kecamatan City Plan }\end{array}$ \\
\hline 3 & $\begin{array}{l}\text { Daerah pemukiman } \\
\text { teratur }\end{array}$ & $\begin{array}{l}\text { Dinas Pemukiman, Pertanahan dan Pertamanan } \\
\text { BAPPELITBANG; BPS; Dinas Penataan Ruang; Kantor } \\
\text { Kecamatan; City Plan }\end{array}$ \\
\hline 4 & $\begin{array}{l}\text { Daerah perumahan tidak } \\
\text { teratur, selokan }\end{array}$ & $\begin{array}{l}\text { Dinas Pemukiman, Pertanahan dan Pertamanan } \\
\text { BAPPELITBANG; BPS; Dinas Penataan Ruang } \\
\text { Kantor Kecamatan; City Plan }\end{array}$ \\
\hline 5 & Daerah industri & $\begin{array}{l}\text { BAPPELITBANG; BPS; Dinas Penataan Ruang } \\
\text { Kantor Kecamatan; City Plan }\end{array}$ \\
\hline 6 & $\begin{array}{l}\text { Jalan, taman, dan hutan } \\
\text { kota }\end{array}$ & $\begin{array}{l}\text { Dinas Pekerjaan umum yang membidangi binamarga; } \\
\text { BAPPELITBANG; Dinas Penataan Ruang; Kantor } \\
\text { Kecamatan }\end{array}$ \\
\hline
\end{tabular}

Sumber : Hasil Analisa, 2018

\subsubsection{Identifikasi jenis data yang tersedia}

\subsubsection{Pemeriksaan kelengkapan data}

Dari sumber data diatas, data yang diperoleh dan kelengkapan data tersebut dapat dilihat pada Tabel 3.3.

\subsubsection{Penentuan pengembangan, modifikasi dan/atau penghilangan sub- parameter}

Dokumen yang digunakan adalah dokumen yang lengkap dan tahun dari pembuatan dokumen tersebut masih layak untuk digunakan. Dari tabel kelengkapan data dapat dilihat bahwa setiap sub-parameter memiliki lebih dari satu dokumen yang bisa digunakan. Penggunaan data tersebut harus disesuaikan dengan parameter yang tercantum dalam SNI, sehingga dilakukan penentuan pengembangan, modifikasi dan atau penghilangan subparameter berdasarkan data yang diperoleh. 


\section{Tabel 3.3 Data yang tersedia dan kelengkapan data}

\begin{tabular}{|c|c|c|}
\hline $\begin{array}{c}\text { Sub- } \\
\text { parameter }\end{array}$ & Jenis data yang tersedia & Kelengkapan data \\
\hline $\begin{array}{l}\text { Daerah di } \\
\text { jalan } \\
\text { protokol/pusat } \\
\text { kota }\end{array}$ & $\begin{array}{l}\text { - Dinas Pekerjaan Umum (PU) yang membidangi } \\
\text { binamarga = panjang dari setiap nama jalan sesuai } \\
\text { kelas jalan } \\
\text { - Dinas Penataan Ruang = panjang jalan setiap } \\
\text { kecamatan dari Kementerian Dalam Negeri tanpa } \\
\text { keterangan tahun } \\
\text { - Kantor Kecamatan = panjang kelas jalan arteri dan } \\
\text { lingkungan Kecamatan Cidadap } \\
\text { - BAPPELITBANG = dokumen Rencana Detail Tata } \\
\text { Ruang (RDTR) Kota Bandung tahun 2011-2031 }\end{array}$ & $\begin{array}{l}\text { - Dinas Pekerjaan Umum (PU) } \\
\text { yang membidangi binamarga = } \\
\text { TIDAK LENGKAP } \\
\text { - Dinas Penataan Ruang = TIDAK } \\
\text { LENGKAP } \\
\text { - Kantor Kecamatan = TIDAK } \\
\text { LENGKAP } \\
\text { - Dokumen Rencana Detail Tata } \\
\text { Ruang (RDTR) = LENGKAP }\end{array}$ \\
\hline $\begin{array}{l}\text { Daerah } \\
\text { komersial }\end{array}$ & $\begin{array}{l}\text { BAPPELITBANG = dokumen Rencana Detail Tata } \\
\text { Ruang (RDTR) Kota Bandung tahun 2011-2031 } \\
\text { BPS = jumlah pasar menurut jenis per kelurahan } \\
\text { tahun 2017, kecuali Kecamatan Sukajadi tahun } 2016 \\
\text { - } \text { Dinas Penataan Ruang = luas lahan perdagangan } \\
\text { setiap kecamatan dari Kementerian Dalam Negeri } \\
\text { tanpa keterangan tahun } \\
\text { - Kantor Kecamatan = Data UMKM Kecamatan Sukajadi, } \\
\text { Cidadap dan Cibeunying Kidul } \\
\text { - City Plan = luas perdagangan dan jasa di setiap } \\
\text { kelurahan }\end{array}$ & $\begin{array}{l}\text { - Dokumen Rencana Detail Tata } \\
\text { Ruang (RDTR) = LENGKAP } \\
\text { - BPS = TIDAK LENGKAP } \\
\text { - Dinas Penataan Ruang = TIDAK } \\
\text { LENGKAP } \\
\text { - Kantor Kecamatan = TIDAK } \\
\text { LENGKAP } \\
\text { - City Plan = LENGKAP }\end{array}$ \\
\hline $\begin{array}{l}\text { Daerah } \\
\text { pemukiman } \\
\text { teratur }\end{array}$ & $\begin{array}{l}\text { - } \text { BAPPELITBANG = dokumen Rencana Detail Tata } \\
\text { Ruang (RDTR) Kota Bandung tahun 2011-2031 } \\
\text { - City Plan = luas perumahan dengan kepadatan } \\
\text { rendah, sedang dan tinggi di setiap kelurahan }\end{array}$ & $\begin{array}{l}\text { - Dokumen Rencana Detail Tata } \\
\text { Ruang (RDTR) = LENGKAP } \\
\text { - City Plan = LENGKAP }\end{array}$ \\
\hline $\begin{array}{l}\text { Daerah } \\
\text { perumahan } \\
\text { tidak teratur, } \\
\text { selokan }\end{array}$ & $\begin{array}{l}\text { - } \text { BAPPELITBANG = dokumen Rencana Detail Tata } \\
\text { Ruang (RDTR) Kota Bandung tahun 2011-2031 } \\
\text { - } \text { City Plan = luas perumahan dengan kepadatan } \\
\text { rendah, sedang dan tinggi di setiap kelurahan }\end{array}$ & $\begin{array}{l}\text { - Dokumen Rencana Detail Tata } \\
\text { Ruang (RDTR) = LENGKAP } \\
\text { - City Plan = LENGKAP }\end{array}$ \\
\hline $\begin{array}{l}\text { Daerah } \\
\text { industri }\end{array}$ & $\begin{array}{l}\text { BAPPELITBANG = dokumen Rencana Detail Tata } \\
\text { Ruang (RDTR) Kota Bandung tahun 2011-2031 } \\
\text { BPS = Jumlah industri menurut klasifikasi per } \\
\text { kelurahan di Kecamatan Sukajadi, Cidadap, } \\
\text { Cibeunying Kaler dan Bandung Wetan } \\
\text { - } \quad \text { Dinas Penataan Ruang = luas lahan perdagangan } \\
\text { setiap kecamatan dari Kementerian Dalam Negeri } \\
\text { tanpa keterangan tahun } \\
\text { - } \quad \text { City Plan = luas industri di setiap kelurahan }\end{array}$ & $\begin{array}{l}\text { - Dokumen Rencana Detail Tata } \\
\text { Ruang (RDTR) = LENGKAP } \\
\text { - BPS = TIDAK LENGKAP } \\
\text { - Dinas Penataan Ruang = TIDAK } \\
\text { LENGKAP } \\
\text { - } \text { Kantor Kecamatan = TIDAK } \\
\text { LENGKAP } \\
\text { - City Plan = LENGKAP }\end{array}$ \\
\hline $\begin{array}{l}\text { Jalan, taman, } \\
\text { dan hutan } \\
\text { kota }\end{array}$ & $\begin{array}{l}\text { - Dinas Pekerjaan umum yang membidangi binamarga } \\
\text { = panjang dari setiap nama jalan sesuai kelas jalan } \\
\text { - } \text { Dinas Penataan Ruang = panjang jalan dan luas } \\
\text { ruang terbuka hijau (RTH) setiap kecamatan dari } \\
\text { Kementerian Dalam Negeri tanpa keterangan tahun } \\
\text { - Kantor Kecamatan = luas taman di Kecamatan } \\
\text { Sukajadi } \\
\text { - } \text { BAPPELITBANG = dokumen jumlah taman di } \\
\text { beberapa kecamatan yang termasuk WP Bandung } \\
\text { Utara } \\
\text { - City Plan = luas RTH di setiap kelurahan }\end{array}$ & $\begin{array}{l}\text { - Dinas Pekerjaan Umum }(P U) \\
\text { yang membidangi binamarga = } \\
\text { TIDAK LENGKAP } \\
\text { - Dinas Penataan Ruang = TIDAK } \\
\text { LENGKAP } \\
\text { - Kantor Kecamatan = TIDAK } \\
\text { LENGKAP } \\
\text { - Dokumen BAPPELITBANG = } \\
\text { TIDAK LENGKAP } \\
\text { - City Plan = LENGKAP }\end{array}$ \\
\hline
\end{tabular}

Sumber : Hasil Analisa, 2018 
Tabel 3.4 Penentuan pengembangan, modifikasi dan/atau penghilangan subparameter

\begin{tabular}{|c|c|c|}
\hline No & Sub-parameter & Pengembangan, modifikasi dan/atau penghilangan \\
\hline 1 & $\begin{array}{l}\text { Daerah di jalan } \\
\text { protokol/pusat } \\
\text { kota }\end{array}$ & $\begin{array}{l}\text { - Berdasarkan RDTR } \text { Kota } \text { Bandung tahun } 2011-2031 \text {, } \\
\text { digabungkan dengan sub-parameter jalan yang kemudian di } \\
\text { modifikasi menjadi sub-parameter jalan arteri }\end{array}$ \\
\hline 2 & Daerah komersial & $\begin{array}{l}\text { - Berdasarkan RDTR tidak ada perubahan } \\
\text { - Berdasarkan dokumen dari City Plan Kota Bandung dimodifikasi } \\
\text { menjadi sub-parameter perdagangan dan jasa }\end{array}$ \\
\hline 3 & $\begin{array}{l}\text { Daerah } \\
\text { pemukiman } \\
\text { teratur }\end{array}$ & $\begin{array}{l}\text { - Berdasarkan RDTR tidak ada perubahan } \\
\text { - Berdasarkan dokumen dari City Plan Kota Bandung digabungkan } \\
\text { dengan daerah perumahan tidak teratur dengan memodifikasi } \\
\text { menjadi kondisi perumahan }\end{array}$ \\
\hline 4 & $\begin{array}{l}\text { Daerah } \\
\text { perumahan tidak } \\
\text { teratur, selokan }\end{array}$ & $\begin{array}{l}\text { - Berdasarkan RDTR tidak ada perubahan } \\
\text { - Berdasarkan dokumen dari City Plan Kota Bandung digabungkan } \\
\text { dengan daerah perumahan tidak teratur dengan memodifikasi } \\
\text { menjadi kondisi perumahan }\end{array}$ \\
\hline 5 & Daerah industri & $\begin{array}{l}\text { - Berdasarkan RDTR dan City Plan Kota Bandung tidak ada } \\
\text { perubahan }\end{array}$ \\
\hline 6 & $\begin{array}{l}\text { Jalan, taman, dan } \\
\quad \text { hutan kota }\end{array}$ & $\begin{array}{l}\text { - Sub-parameter jalan digabungkan dengan daerah jalan protokol } \\
\text { menjadi jalan arteri } \\
\text { - Taman dan hutan kota dimodifikasi menjadi RTH berdasarkan } \\
\text { data dari City Plan Kota Bandung }\end{array}$ \\
\hline
\end{tabular}

\subsubsection{Penentuan data yang digunakan}

Berdasarkan kelengkapan, keseragaman dan tahun dari sumber data, maka data yang digunakan untuk perencanaan ini yaitu :

1. Daerah di jalan protokol/pusat kota dan selokan: panjang jalan arteri dalam peta dasar RDTR Kota Bandung tahun 2011-2031 dengan mengukur menggunakan aplikasi Arc GIS. Berdasarkan hasil wawancara terhadap Dinas PU Bina Marga dan Dinas Tata Ruang, panjang jalan rencana di dalam RDTR hampir seluruhnya sudah sesuai dengan kondisi lapangan kecuali untuk SWK Arcamanik dan SWK Gedebage.

2. Daerah komersial : luas setiap perdagangan dan jasa dari City Plan Kota Bandung.

3. Daerah perumahan diambil dari City Plan Kota Bandung. Data yang tersedia dari City Plan sendiri berupa kondisi perumahan dengan kepadatan rendah, sedang dan tinggi.

4. Daerah industri : data yang digunakan adalah luas lahan daerah industri dari City Plan Kota Bandung, karena data dari Kemendagri yang diperoleh dari dinas tata ruang tidak ada keterangan tahun pengambilan data dan hanya ada beberapa kekelurahan yang tersedia.

5. Jalan, taman dan hutan kota : luas lahan ruang terbuka hijau (RTH) dari City Plan Kota Bandung yang digunakan untuk perencanaan ini, karena data ini lebih lengkap untuk seluruh kelurahan dibandingkan sumber data lainnya.

Pengembangan, modifikasi dan/atau penghapusan sub-parameter dalam parameter fungsi dan nilai daerah yang dilakukan berdasarkan ketersediaan data adalah sebagai berikut:

a. Sub-parameter daerah di jalan protokol dan jalan digabungkan menjadi jalan arteri, hal ini karena menurut Peraturan Pemerintah Republik Indonesia tentang jalan, jalan diklasifikasikan menjadi 2 yaitu berdasarkan fungsinya dan berdasarkan statusnya. Jalan arteri merupakan jalan di pusat kota atau jalan utama. Dari klasifikasi tersebut tidak ada jalan protokol. Sedangkan jalan protokol adalah sebutan untuk jalan besar 
yang berada di pusat kota. Sehingga jika mengacu pada peraturan tersebut, jalan arteri dapat menggantikan sub-parameter daerah di jalan protokol dan jalan, dengan asumsi daerah jalan sama panjangnya dengan jalan tersebut. Data yang digunakan adalah jalan arteri primer karena dari data yang diperoleh hanya ada data arteri primer di Wilayah Pelayanan Bandung Utara. Data jalan arteri primer diperoleh dengan cara mengukur panjang jalan dari peta dasar jalan dalam RDTR Kota Bandung tahun 2011 - 2031 menggunakan aplikasi Arc GIS.

b. Sub-parameter daerah komersial dimodifikasi menjadi perdagangan dan jasa. Di dalam Kamus Besar Bahasa Indonesia atau KBBI, daerah komersial merupakan daerah yang memiliki kegiatan berhubungan dengan perdagangan dan/atau yang menghasilkan keuntungan. Dari penjelasan tersebut dapat dikatakan bahwa perdagangan adalah bentuk kegiatan dari daerah komersil sedangkan jasa merupakan kegiatan yang menghasilkan keuntungan, sehingga data luas perdagangaan dan jasa dapat mewakili daerah komersil.

c. Sub-parameter daerah perumahan teratur dan tidak teratur digabungkan menjadi 1 (satu) sub-parameter yaitu kondisi perumahan. Sub-parameter kondisi perumahan terdiri dari 2 indikator yakni kondisi perumahan dengan kepadatan rendah dan kepadatan tinggi. Perubahan sub-parameter ini berdasarkan asumsi bahwa kondisi perumahan kepadatan rendah akan lebih teratur dibandingkan dengan perumahan kepadatan tinggi. Sehingga kondisi perumahan dengan kepadatan rendah dapat mewakili sub-parameter kondisi perumahan teratur dan kondisi perumahan dengan kepadatan tinggi dapat mewakili kondisi perumahan tidak teratur. Sedangkan untuk sub-parameter selokan dihilangkan karena berdasarkan dokumen yang diperoleh dari instansi-instansi diatas tidak terdapat data untuk selokan.

d. Sub-parameter daerah industri tidak ada perubahan, data yang digunakan adalah luas dari daerah industri

e. Sub-parameter taman dan hutan kota diubah menjadi Ruang Terbuka Hijau (RTH). Menurut Instruksi Kementrian Dalam Negeri Nomor 14 Tahun 1988 tentang Penataan Ruang Terbuka Hijau di Wilayah Perkotaan, Ruang Terbuka Hijau atau RTH merupakan bagian dari penataan ruang kota yang berfungsi sebagai kawasan hijau pertamanan kota, kawasan hijau hutan kota, kawasan hijau rekreasi kota, kawasan hijau kegiatan olahraga, kawasan hijau pemakaman, kawasan hijau pertanian, kawasan hijau jalur hijau dan kawasan hijau pekarangan. Berdasarkan literatur tersebut dan ketersediaan data di lapangan, maka RTH dapat dijadikan subparameter pengganti taman dan hutan kota dalam parameter fungsi dan nilai daerah karena taman dan hutan kota merupakan bagian dari RTH. Data yang digunakan adalah luas RTH.

\subsection{Penyusunan penilaian penentuan daerah prioritas berdasarkan parameter fungsi dan nilai daerah}

Penyusunan penilaian dilakukan dengan membuat kriteria penilaian dari masing-masing subparameter yang kemudian dilakukan skoring dan pembobotan dengan berdasarkan data dan justifikasi yang mengacu pada literature. Berikut ini adalah pembahasan dari masing-masing tahap penilaian.

\subsubsection{Pembuatan standar kelas penilaian dan skoring}

Pembuatan standar kelas ini berdasarkan pada perbandingan nilai terbesar dengan nilai terkecil yang kemudian dibagi sesuai kelas yang diinginkan untuk selanjutnya di kelompokkan sesuai selisih antar kelas. Dalam perencanaan ini setiap sub-parameter dibuat menjadi 3 standar kelas penilaian untuk menyesuaikan dengan kriteria penilaian parameter lain. Setelah pembuatan standar kelas untuk masing-masing sub-parameter, selanjutnya 
dilakukan scoring. Skoring ini dilakukan berdasarkan tingkat kepentingan sub-parameter tersebut sehingga harus di prioritaskan dalam pengelolaan sampahnya. Semakin tinggi nilai skor maka diasumsikan daerah tersebut semakin prioritas, begitupun sebaliknya. Berikut ini adalah standar kelas dan skor untuk sub-parameter dengan justifikasi tingkat kepentingan dari masing-masing sub-parameter dalam parameter fungsi dan nilai daerah.

a. Jalan Arteri

Panjang jalan arteri terpendek yaitu 0 m, dan terpanjang 1740,249 m

Sehingga dengan begitu standar kelas penilaian yakni :
1) Rendah ( $0 \mathrm{~m}-580,083 \mathrm{~m})$
: Skor 1
2) Sedang $(580,084 \mathrm{~m}-1160,166 \mathrm{~m})$
: Skor 2
3) Tinggi $(1160,167 \mathrm{~m}-1740,249 \mathrm{~m})$
: Skor 3

Semakin panjang jalan arteri makan skornya akan semakin tinggi, karena semakin panjang jalan arteri akan sama dengan daerah tersebut berada dikawasan kota sehingga akan semakin di prioritaskan.

b. Ruang Terbuka Hijau (RTH)

Luas RTH terbesar yaitu 90,947 $\mathrm{Ha}$ dan terkecil sebesar $0 \mathrm{Ha}$, standar kelas penilaiannya adalah :
1) Rendah (0 $\mathrm{Ha}-30,315 \mathrm{Ha})$
: Skor 3
2) Sedang $(30,316 \mathrm{Ha}-60,631 \mathrm{Ha})$
: Skor 2
3) Tinggi $(60,631 \mathrm{Ha}-90,947 \mathrm{Ha})$
: Skor 1

Komposisi sampah yang dihasilkan pada RTH lebih ramah lingkungan dibandingkan non RTH. Daerah prioritas adalah daerah yang harus dilayani lebih intens dibandingkan daerah lain untuk menghindari adanya pencemaran lingkungan yang diakibatkan dari sampah tersebut. Dari penjelasan tersebu, maka daerah yang harus diprioritaskan adalah luas RTH yang lebih kecil atau daerah yang lebih banyak non RTH dibandingkan RTH nya.

C. Daerah Industri

Luas daerah industri terbesar yaitu $0 \mathrm{Ha}$ dan terkecil yaitu sebesar 8,238 $\mathrm{Ha}$, standar kelas penilaian sebagai berikut.
1) Rendah ( $0 \mathrm{Ha}-2,746 \mathrm{Ha})$
: Skor 1
2) Sedang $(2,747 \mathrm{Ha}-5,492 \mathrm{Ha})$
: Skor 2
3) Tinggi $(5,493 \mathrm{Ha}-90,947 \mathrm{Ha})$
: Skor 3

Semakin besar luas daerah industri maka sampah yang dihasilkan semakin besar, maka daerah tersebut harus diprioritaskan agar sampah yang dihasilkan tidak mencemari lingkungan dan berdampak lebih lanjut.

d. Perdagangan dan jasa

Luas perdagangan dan jasa untuk Wilayah Pelayanan Bandung Utara terbesar yakni $58,811 \mathrm{Ha}$ dan terendah sebesar 1,253 Ha, sehingga dapat diperoleh standar kelas penilaian.
1) Rendah (1,253 $\mathrm{Ha}-20,439 \mathrm{Ha})$
: Skor 1
2) Sedang $(20,440 \mathrm{Ha}-39,625 \mathrm{Ha})$
: Skor 2
3) Tinggi $(39,626 \mathrm{Ha}-58,811 \mathrm{Ha})$
: Skor 3

Timbulan sampah yang dihasilkan dari kegiatan perdagangan dan jasa akan semakin banyak jika luas perdagangan dan jasa pun semakin besar. Maka skor lebih besar untuk luas perdagangan jasa yang lebih besar dan skor lebih kecil untuk luas perdagangan dan jasa yang lebih kecil.

e. Kondisi Perumahan

Sub-Parameter kondisi perumahan terdiri dari dua indikator yakni kondisi perumahan dengan kepadatan rendah (PKR) dan kepadatan tinggi (PKT), untuk luas terbesar kondisi perumahan dengan kepadatan rendah yaitu 113,760 Ha dan terkecil 0,101 $\mathrm{Ha}$. Berbeda dengan sub-parameter lain, untuk kondisi perumahan dilakukan scoring 
3 kali. Hal ini karena didalam sub-parameter ini memiliki 2 indikator yang harus digabungkan menjadi 1 skor. Skoring pertama yang dilakukan yaitu untuk indikator kondisi perumahan dengan kepadatan rendah (PKR)
1) Rendah (0 $\mathrm{Ha}-37,919 \mathrm{Ha})$
: Skor 3
2) Sedang $(37,920 \mathrm{Ha}-75,840 \mathrm{Ha}) \quad$ : Skor 2
3) Tinggi $(75,841 \mathrm{Ha}-113,760 \mathrm{Ha}) \quad$ : Skor 1

Semakin besar luas PKR sama dengan semakin besar luas perumahan teraturnya. Semakin besar luas perumahan teratur maka pengelolaan sampah akan semakin mudah untuk dikelola. Semakin mudah daerah untuk dikelola sampahnya maka semakin tidak prioritas.

Kemudian scoring kedua untuk indikator kondisi perumahan kepadatan tinggi (PKT) dengan luas terbesar 79,739 Ha dan terkecil 0,501 Ha yaitu:
1) Rendah (0 Ha - 26,580 Ha)
: Skor 1
2) Sedang $(26,581 \mathrm{Ha}-53,159 \mathrm{Ha})$
: Skor 2
3) Tinggi $(53,160 \mathrm{Ha}-79,739 \mathrm{Ha})$
: Skor 3

Luas PKT sama dengan luas perumahan tidak teratur, jika luas perumahan tidak teratur disuatu daerah semakin besar maka akan lebih sulit pengaplikasian sistem pengelolaan sampahnya. Sehingga daerah tersebut harus lebih diprioritaskan untuk menghindari dampak yang ditimbulkan dari tidak terkelolanya sampah bagi kesehatan masyarakat setempat.

Dari kedua indikator yang telah di scoring tersebut kemudian digabungkan ke dalam satu kriteria penilaian untuk sub-parameter kondisi perumahan. Berikut ini adalah standar kelas penilaian untuk kondisi perumahan.

1) PKR dan PKT sama tinggi

: Skor 3

2) PKR rendah dan PKT tinggi

: Skor 2

3) PKR tinggi dan PKT rendah atau PKR dan PKT sama rendah

: Skor 1

Standar kelas penilaian diatas diambil dari hasil scoring indikator sebelumnya, dalam hasil scoring diperoleh 3 (tiga) macam data yakni PKR dan PKT tinggi atau skor sama dengan 3 berarti bahwa kondisi daerah tersebut padat dan tidak teratur, PKR rendah dan PKT tinggi atau skor 3 dan 2 atau 1 yang artinya kondisi daerah padat penduduk, PKR tinggi dan PKT rendah atau skor 1 atau 2 dan 3 sama dengan kondisi daerah dengan kepadatan sedang, PKR dan PKT sama rendah atau skor sama dengan 1 yang berarti daerah kepadatan rendah dan teratur. Skor untuk standar kelas penilaian kondisi perumahan sendiri sama dengan asumsi kedua indikator sebelumnya, semakin padat dan tidak teratur maka semakin prioritas.

Berikut ini contoh perhitungan penentuan standar kelas dari daerah industri.

Diketahui :

- $\quad$ Luas daerah industri $=0 \mathrm{Ha}$

- Luas daerah industri $=8,238 \mathrm{Ha}$

Ditanyakan : Tentukan standar kelas dengan jumlah kelas 3

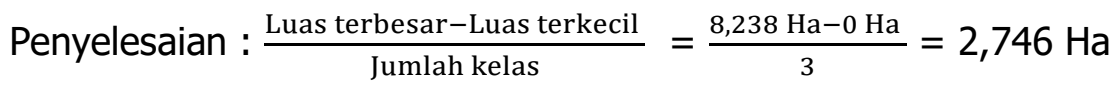

Sehingga standar kelas penilaian adalah :

\begin{tabular}{|c|c|}
\hline Rendah & $0 \mathrm{Ha}-2,746 \mathrm{Ha}$ \\
\hline Sedang & $2,747 \mathrm{Ha}-5,492 \mathrm{Ha}$ \\
\hline Tinggi & $5,493 \mathrm{Ha}-8,238 \mathrm{Ha}$ \\
\hline
\end{tabular}

\subsubsection{Pembobotan nilai akhir berdasarkan SNI}


Hasil yang diharapkan dalam pembobotan nilai akhir ini adalah daerah prioritas untuk pengelolaan sampah di Wilayah Pelayanan Bandung Utara berdasarkan parameter fungsi dan nilai daerah dari hasil skoring masing-masing sub-parameter. Pembobotan ini mengacu pada skala prioritas penilaian kerawanan sanitasi dan potensi ekonomi yang tercantum dalam SNI. Semakin besar nilai dari pembobotan ini maka daerah tersebut semakin prioritas. Berikut ini nilai kerawanan sanitasi dan potensi ekonomi dari subparameter fungsi dan nilai daerah tercantum dalam Tabel 3.5.

Tabel 3.5 Nilai Kerawanan Sanitasi dan Potensi Ekonomi

\begin{tabular}{cccc}
\hline No & Sub-Parameter & $\begin{array}{c}\text { Kerawanan } \\
\text { Sanitasi }\end{array}$ & $\begin{array}{c}\text { Potensi } \\
\text { Ekonomi }\end{array}$ \\
\hline 1 & Jalan Arteri & 3 & 4 \\
\hline 2 & RTH & 3 & 1 \\
\hline 3 & Daerah Industri & 2 & 4 \\
\hline 4 & $\begin{array}{c}\text { Perdagangan dan } \\
\text { Jasa }\end{array}$ & 3 & 5 \\
\hline 5 & Kondisi Perumahan & 4 & 4
\end{tabular}

Sumber : Hasil Analisa, 2018

Kerawanan sanitasi (KS) dan potensi ekonomi (PE) dari sub-parameter kondisi perumahan mengalami perubahan, karena pada SNI yang tercantum yaitu kerawanan sanitasi dan potensi ekonomi untuk sub-parameter perumahan teratur dan tidak teratur. Yang tercantum dalam SNI dikembangkan menjadi satu sub-parameter kondisi perumahan. Hal yang dilakukan yaitu membagi secara rata kedua nilai kerawanan sanitasi dan potensi ekonomi. Perhitungan yang dimaksud adalah sebagai berikut :

Diketahui : Nilai KS dan PE untuk perumahan teratur $=4 \& 4$

Nilai KS dan PE untuk perumahan tidak teratur $=5 \& 1$

Ditanyakan : Nilai KS dan PE untuk kondisi perumahan

Penyelesaian :

Nilai KS kondisi perumahan $=\frac{\text { Nilai KS perumahan teratur+Nilai KS perumahan tidak teratur }}{2}$

$$
=\frac{4+5}{2}=4,5
$$

Nilai PE kondisi perumahan $=\frac{\text { Nilai PE perumahan teratur+Nilai PE perumahan tidak teratur }}{2}$

$$
=\frac{4+1}{2}=2,5
$$

Sehingga nilai kerawanan sanitasi untuk kondisi perumahan yaitu 4,5 dan nilai potensi ekonomi yaitu 2,5 .

Nilai kerawanan sanitasi dan potensi ekonomi diatas kemudian dikalikan dengan skor yang telah dibuat sebelumnya. Dari hasil perkalian selanjutnya dijumlahkan dan dibuat standar kelas untuk menentukan daerah prioritas.

Contoh perhitungan penilaian sub-parameter fungsi dan nilai daerah berdasarkan kerawanan sanitasi dan potensi ekonomi yang tercantum dalam SNI.

Diketahui : Skor jalan arteri untuk Kelurahan Ciumbuleuit $=1$

Kerawanan sanitasi untuk jalan arteri $=3$ 
Potensi ekonomi untuk jalan arteri $=4$

Ditanyakan : Nilai sub-parameter jalan arteri

Penyelesaian : (Skor x Kerawanan sanitasi) + (Skor $x$ Potensi ekonomi)

$=(1 \times 3)+(1 \times 4)=7$

Perhitungan terakhir yaitu melakukan pembobotan nilai untuk penentuan daerah prioritas seperti contoh dibawah ini:

Diketahui : Nilai jalan arteri $=7$, nilai $\mathrm{RTH}=4$, nilai daerah industri $=6$, nilai perdagangan dan jasa $=16$, nilai kondisi perumahan $=7$

Ditanyakan : a. Nilai akhir, b. Skala prioritas jika 3 kelas

Penyelesaian :

a. Nilai akhir

Nilai akhir dapat dihitung dengan menjumlahkan seluruh nilai dari masing-masing subparameter

Nilai akhir = nilai jalan arteri + nilai RTH + nilai daerah industri + nilai perdagangan dan jasa + nilai kondisi perumahan

b. Skala prioritas

$$
=7+4+6+16+7=40
$$

Penentuan daerah prioritas berdasarkan standar kelas. Nilai terbesar dari fungsi dan nilai daerah adalah 68 dan terkecil adalah 40.

Penyelesaian : $=\frac{\text { Nilai terbesar-Nilai terkecil }}{\text { Jumlah kelas }}=\frac{68-40}{3}=9$

Untuk kelas 1 yaitu $40+9=48$ (nilai 40 termasuk dalam perhitungan 9), begitupun selanjutnya hingga nilai tertinggi yakni 68 .

Berikut ini merupakan skala prioritas berdasarkan standar kelas tersebut : Daerah Prioritas $3=40-48$, Daerah Prioritas $2=49-58$, Daerah Prioritas $1=59-68$

\subsubsection{Pembuatan peta daerah prioritas}

Pembuatan peta dilakukan dengan aplikasi Arc GIS. Setiap warna di setiap kelurahan berbeda sesuai dengan tingkat prioritas kelurahan tersebut. Berikut ini peta yang dihasilkan dari perencanaan ini tercantum dalam Gambar $\mathbf{3 . 1}$

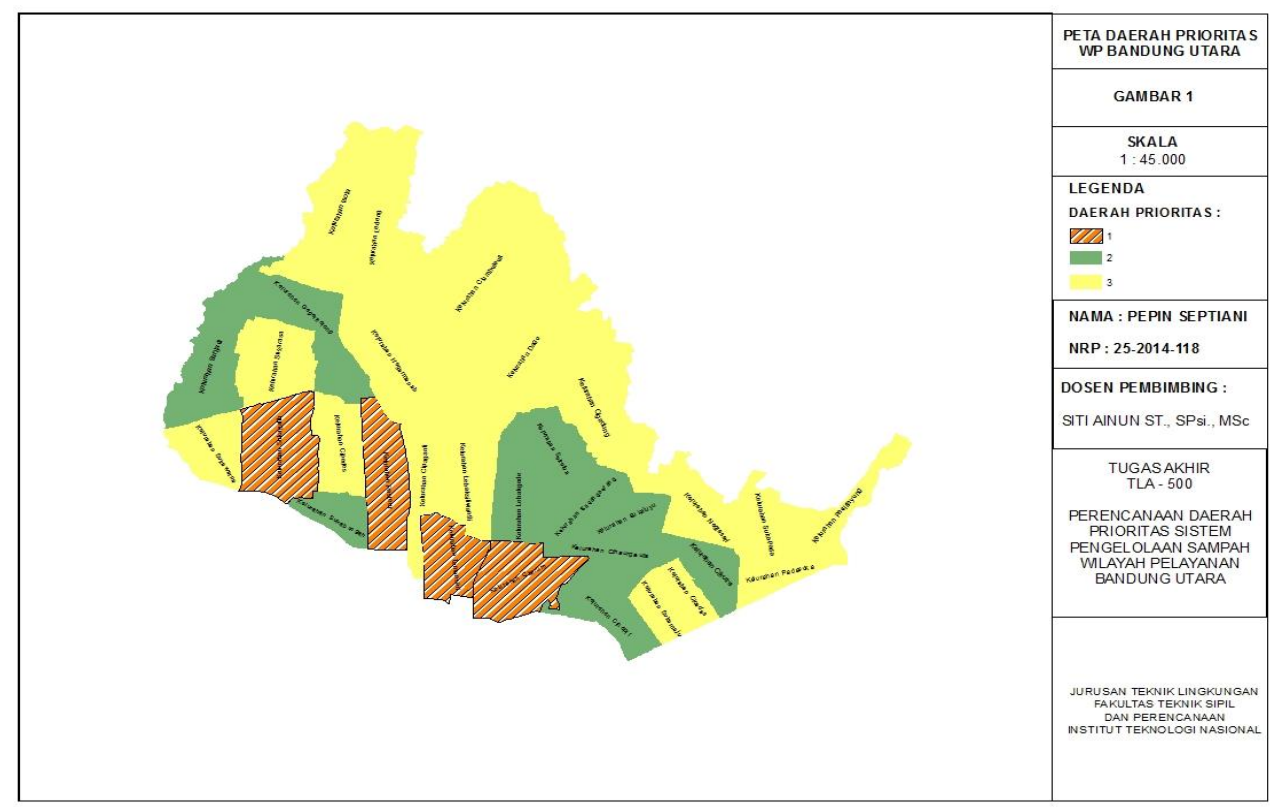




\section{Gambar 3.1 Daerah Prioritas Wilayah Pelayanan Bandung Utara}

Sumber : Hasil Analisa, 2018

\section{KESIMPULAN}

Berdasarkan data yang diperoleh dan studi literature, sub-parameter dalam parameter fungsi dan nilai daerah untuk penentuan daerah prioritas yang tercantum dalam SNI 19-2454-2002 tentang Tata cara Pengelolaan Sampah Perkotaan bagian diperlukan perubahan, hal ini disebabkan karena peraturan tersebut sudah cukup lama serta kriteria penilaian yang ada tidak jelas dan ketersediaan data di lapangan tidak memenuhi. Sub-parameter yang telah diubah antara lain menjadi kondisi perumahan, daerah industri, perdagangan dan jasa, ruang terbuka hijau (RTH) dan jalan arteri. Dari hasil analisa, daerah prioritas 1 di Wilayah Pelayanan Bandung Utara berdasarkan fungsi dan nilai daerah terdiri dari 4 kelurahan, daerah prioritas 2 terdiri dari 10 kelurahan dan daerah prioritas 3 terdiri dari 17 kelurahan.

\section{DAFTAR RUJUKAN}

Anonim. (2018). Kamus Besar Bahasa Indonesia Online. Kbbi.web.id. diakses pada 7 Juni 2018, pukul 20.23 WIB. Bandung.

Bandung, B. P. S. K. (2017). Kecamatan Dalam Angka 2017. Badan Pusat Statistik Kota Bandung, Bandung.

Bappeda Kota Bandung. (2011). Laporan penyusunan perencanaan penanganan persampahan di daerah aliran anak sungai citarum. Kota Bandung.

BAPPELITBANG. (2011). Laporan Penyusunan RDTR Kota Bandung Tahun 2011 - 2031. Kota Bandung.

Damanhuri, E., dan Padmi, T. (2016). Pengelolaan sampah terpadu. Diktat Kuliah TL, 3104, 5-10.

Dinas Bina Marga. (2016). Daftar Ruas Jalan Menurut Fungsi di Wilayah Kota Bandung. Kota Bandung.

Dinas Tata Ruang Kota Bandung. (2016). Laporan pekerjaan penyusunan standar sarana dan prasarana minimal hunian dan non hunian di Kota Bandung. Kota Bandung.

Nasional, B. S. (2002). SK SNI 19-2454-2002 Tentang Tata Cara Teknik Operasional Pengolahan Sampah Perkotaan. Jakarta: Balitbang DPU.

Plan, City . (2017). Perencanaan Tata Ruang Kota Bandung. City Plan Kota Bandung, Bandung.

Rencana Detail Tata Ruang Kota Bandung Tahun 2011 - 2031 